Tropical Journal of Pharmaceutical Research, March 2008; 7 (1): 929-934

(c) Pharmacotherapy Group, Faculty of Pharmacy, University of Benin, Benin City, Nigeria.

All rights reserved.

\title{
Antimicrobial Susceptibility of Community-associated Staphylococcus aureus Isolates from Healthy Women in Zaria, Nigeria
}

\author{
Adebola Onanuga $^{1,2}$ and Josiah A Onaolapo ${ }^{1}$ \\ ${ }^{1}$ Department of Pharmaceutics and Pharmaceutical Microbiology, Faculty of Pharmaceutical Sciences, Ahmadu Bello \\ University, Zaria, Nigeria; ${ }^{2}$ Department of Pharmaceutical Microbiology and Biotechnology, Faculty of Pharmacy, \\ Niger Delta University, Wilberforce Island, Amasoma Bayelsa State, Nigeria.
}

\begin{abstract}
Purpose: An investigation of the antimicrobial susceptibility patterns of Staphylococcus aureus isolated from healthy women to ten commonly used antimicrobial drugs was carried out as a basis for a guide for empirical antimicrobial treatment using urine samples.

Method: The samples collected from healthy women volunteers in Zaria were cultured and screened for $S$. aureus using standard microbiological procedures. The antimicrobial susceptibility of the isolates was investigated using disc diffusion technique.

Result: A total of 54(36\%) S. aureus isolates were isolated from 150 urine samples collected. Of the 54 isolates, 16 (29.6\%), 15 (27.8\%) and $23(42.6 \%)$ were from married but not pregnant, pregnant and single women respectively. The isolates were highly susceptible to ciprofloxacin, gentamicin, ofloxacin, sparfloxacin and pefloxacin in both groups (married and single). The differences observed in all the antimicrobial drugs tested for both groups were not statistically significant ( $p>0.05)$. A total of $34(63 \%)$ of the isolates showed multi-drug resistance and only $6(11 \%)$ were susceptible to all the antimicrobial drugs tested.

Conclusion: This observation calls for measures to reduce the reservoir of antimicrobial resistant organisms in healthy populations.
\end{abstract}

Key words: Antimicrobial drugs, community-associated, susceptibility, Staphylococcus aureus, healthy women.

*Corresponding Author: E-mail: adebolaonanuga@yahoo.co.uk 


\section{INTRODUCTION}

Staphylococcus aureus is a worldwide pathogen with its natural reservoir in human. It is one of the most common causes of severe community associated infections of skin and soft tissue ${ }^{1,2}$. Treatment of serious $S$. aureus infections can be challenging, and the associated mortality rate remains $20 \%$ to $25 \%$ despite the availability of highly active antimicrobial drugs ${ }^{3}$.

S. aureus colonises the nares, axillae, vagina and damaged skin surfaces. About $30 \%$ to $50 \%$ of healthy adults are colonised with 10 to $20 \%$ persistently colonised ${ }^{4}$. Approximately $60 \%$ of women harbour this organism intermittently at one or more body sites ${ }^{5}$ Studies have shown that $7-25 \%$ of women harbour toxin-producing S. aureus ${ }^{6}$. Persons colonised with $S$. aureus strains are at increased risk of becoming infected with these strains $^{1,7}$

In the early 1950s, penicillinase-producing strains were universally present in hospital while community-associated isolates of $S$. aureus were considered to be largely penicillin susceptible. However, over the past few years, community-associated $S$. aureus infections are not only resistant to penicillin but to all other $\beta$ - lactam antibiotics ${ }^{8,9}$. More so, it is known that epidemic strains of $S$. aureus are commonly resistant to many antimicrobial drugs thereby making the choice of appropriate therapy difficult.

We hereby report the antimicrobial susceptibility pattern of community associated $S$. aureus isolated from healthy women in Zaria community as guide for empirical antimicrobial treatment and a basis for their reduction in healthy communities. This is relevant since resistance is believed to be a common phenomenon among strains of this organism, which is a likely result of indiscriminate use of antimicrobial drugs, a common occurrence in most Nigerian communities.

\section{MATERIALS AND METHODS Sample Collection}

First "clean catch" urine samples were collected randomly from 150 healthy women of three (3) categories (single, married but not pregnant, and pregnant women of ages between 20-40 years) over a period of two (2) months from Zaria community after informed consent had been obtained from each woman. All the volunteers were not on any antimicrobial drug at the point of sampling. Samples (Fifty from each group) were collected into labelled sterile bottles, kept in an iced-bag and transported to the laboratory.

\section{Bacteriology}

Within two (2) hours of collection, each urine sample was inoculated (in duplicates) into Mannitol salt agar plates on arrival at the laboratory. The plates were incubated aerobically at $37^{\circ} \mathrm{C}$ for 24 hours. The characteristic isolates were identified using colonial, morphological and biochemical characteristics as described by Cheesbrough 10. Isolates that were Gram-positive cocci, catalase positive and coagulated human plasma were considered as $S$. aureus in this study.

\section{Definition of Community-associated Isolates}

For the purpose of this study, communityassociated isolates were defined as isolates from the samples of the healthy women who were not on any antimicrobial drug at the time of sampling and had not been admitted in hospital in the last one year.

\section{Antimicrobial Susceptibility testing}

Antimicrobial susceptibility pattern of all isolated $S$. aureus to the following ten (10) commonly used antimicrobial drugs in the community [ampicillin 10 $\mu$ g (Medreich sterilab, India), cephalexin 30 $\mu$ g (Fidson, India), ciprofloxacin (ciprotab ${ }^{\circledR}$ ) $5 \mu g$ (Fidson, India), clindamycin (Dalacin $\mathrm{C}^{\circledR}$ ) $2 \mu \mathrm{g}$ (Pharmacia, Belgium), gentamicin (Hefogenta ${ }^{\circledR}$ ) $10 \mu \mathrm{g}$ (Wuham, china), methicillin $10 \mu g$ (Oxoid, UK), ofloxacin (Fluxor $\left.{ }^{\circledR}\right) 5 \mu$ (Pathoteq Lab, India), pefloxacin $\left(\right.$ Peflotab $\left.^{\circledR}\right) 5 \mu g$ (Fidson, India), Sparfloxacin (Sparbact $^{\circledR}$ ) $5 \mu g$ (Pathoteq Lab. 
India) and vancomycin $30 \mu \mathrm{g}$ (DumexAlpharma, S. Demark)] were determined by the modified Kirby-Bauer diffusion technique 10. Standardised overweight culture of each isolates (containing about $10^{8} \mathrm{cfu} / \mathrm{ml}$ ) was used to flood the surface of Mueller Hinton agar (MHA) plates; the excess was drained off and the surface was allowed to dry aseptically. The standard antimicrobial discs were then aseptically placed at reasonable equidistance on the inoculated MHA plates and allowed to stand for 1 hour. The plates (prepared in duplicate for each isolate) were then incubated at $37^{\circ} \mathrm{C}$ for 18 hours ${ }^{~}$. The diameter of the zone of inhibition produced by each antimicrobial disc was measured, recorded and isolates were classified as "resistant", "intermediate sensitive" or sensitive (susceptible) based on the standard interpretative chart updated according to the current the National Committee for Clinical Laboratory standards (NCCLS; now the Clinical and Laboratory Standards Institute [CLSI] guidelines ${ }^{11}$.

\section{Statistical Analysis}

Frequencies were obtained and percentages were calculated for study variables. Chisquare and two tailed Fisher's exact test were used to calculate probabilities and determine significance. A p-value of less than or equal to 0.05 is considered to be statistically significant $(p \leq 0.05)$.

\section{RESULTS}

Fifty-four (36\%) out of 150 urine samples of healthy women volunteers screened yielded $S$. aureus isolates. The distribution of $S$. aureus isolates among the groups of women showed that it is more prevalent in the singles than the two groups of married women (Table 1).

The antimicrobial susceptibility test results in Table 2 show that the isolates from all the groups were generally highly susceptible to ciprofloxacin, gentamicin, ofloxacin, pefloxacin and sparfloxacin. They have generally very low susceptibility to ampicillin, cephalexin, clindamycin, methicillin and vancomycin. The observed differences in the susceptibility of the isolates from the two groups of women to the tested antimicrobial drugs is not statistically significant $(p>0.05)$.

Multi-drug resistance in this study was taken as resistance to four or more of the ten antimicrobial drugs tested. The results showed $34(63 \%)$ of the isolates as multi-drug resistant and were methicillin resistant Staphylococcus aureus (MRSA). Only 6 (11\%) of the isolates were fully susceptible to all the tested antimicrobial drugs. The distribution of prevalence of multi-drug resistant $S$. aureus is shown in Figure 1.

\section{DISCUSSION}

$S$. aureus is a virulent organism that is renowned for its potential to acquire resistance to antimicrobial agents and it is one of the common cause of community-acquired and nosocomial infections ${ }^{3}$.

Analysis of the healthy women urine in this study gave a total prevalence rate of $36 \%$, which supported previous reports of studies carried out in Zaria $^{8}$ and Abuja ${ }^{9}$. This result points to the increasing importance of this organism as a urinary pathogen and genital colonizers in our society. It may equally infer correspondingly high prevalence in healthy children and men because of the role of women (as mothers and wives) in our society. Further, broader based studies should be carried out to ascertain this postulation. The difference in the colonization rate of $S$. aureus in the married and single women was not significant $(p>0.05)$ indicating that marital status is not a notable factor in colonization and there is no activity or behaviour of any of the groups, which predisposes them to $S$. aureus infection.

As expected the highest antimicrobial resistance was observed in ampicillin (77\%) in both groups. This continuing upward trend has been noted in other studies ${ }^{8,9,12}$. Resistance to cephalexin and clindamycin is in conformity with previous observations that most isolates of $S$. aureus are resistant to large number of commonly prescribed antibiotics ${ }^{13}$. The low 
Table 1: Frequency of isolation of Staphylococcus aureus from the three groups of women tested.

\begin{tabular}{|c|c|c|c|}
\hline Source & $\begin{array}{l}\text { Number of } \\
\text { Samples }\end{array}$ & $\begin{array}{r}\text { Presence o } \\
\text { no }\end{array}$ & $\begin{array}{l}\text { aureus } \\
(\%)\end{array}$ \\
\hline Married & 50 & 16 & $(32)$ \\
\hline Pregnant & 50 & 15 & (30) \\
\hline Single & 50 & 23 & (46) \\
\hline Total & 150 & 54 & (36) \\
\hline
\end{tabular}

Table 2: Antimicrobial susceptibility profiles of $S$. aureus isolates from urine samples of the women tested.

\begin{tabular}{|c|c|c|c|c|c|}
\hline \multirow{3}{*}{ Antimicrobial drugs } & \multicolumn{5}{|c|}{ Isolates sensitive to antimicrobial drugs } \\
\hline & \multicolumn{2}{|c|}{$\begin{array}{l}{ }^{*} \text { Married } \\
N=31\end{array}$} & \multicolumn{2}{|c|}{$\begin{array}{l}\text { Single } \\
N=23\end{array}$} & \multirow[b]{2}{*}{ P-value } \\
\hline & no & (\%) & no & (\%) & \\
\hline Ampicillin $10 \mu g$ & 4 & (12.9) & 3 & (13.0) & 1.0 \\
\hline Cephalexin $30 \mu g$ & 10 & (32.3) & 7 & $(30.0)$ & 1.0 \\
\hline Ciprofloxacin $5 \mu g$ & 24 & (77.4) & 19 & (82.6) & 0.741 \\
\hline Clindamycin $2 \mu g$ & 5 & (16.1) & 9 & (39.1) & 0.068 \\
\hline Gentamicin $10 \mu g$ & 26 & (83.9) & 22 & (95.7) & 0.224 \\
\hline Methicillin $10 \mu g$ & 10 & (32.3) & 7 & (30.4) & 1.0 \\
\hline Ofloxacin $5 \mu g$ & 24 & $(77.4)$ & 19 & (82.6) & 0.741 \\
\hline Pefloxacin $5 \mu g$ & 24 & (77.4) & 16 & (69.6) & 0.546 \\
\hline Sparfloxacin $5 \mu g$ & 25 & $(80.6)$ & 20 & (87.0) & 0.717 \\
\hline Vancomycin $30 \mu g$ & 9 & $(29.0)$ & 9 & $(39.1)$ & 0.561 \\
\hline
\end{tabular}

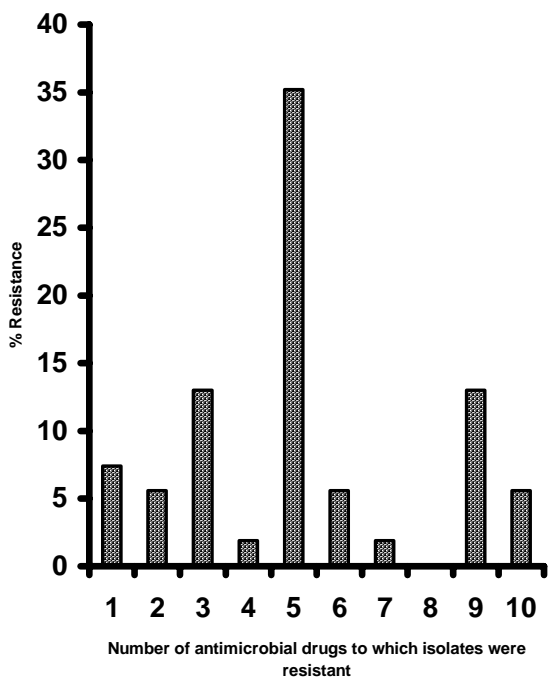

Figure 1: Distribution of prevalence of multi-drug resistant Staphylococcus aureus susceptibility observed in methicillin and 
vancomycin $(30-40 \%)$ in the two groups support the previous reports in our communities ${ }^{14,15}$. The resistance may be due to the acquisition of resistance determining genes, such as mecA (methicillin), van $A, B, C$ responsible for vancomycin resistance in enterococci 16,17 or as a result of the thickening of the cell wall as reported by some authors 17, ${ }^{18}$. These were however not determined in this work. A total of $70-96 \%$ of the isolates was highly susceptible to gentamicin, ofloxacin, ciprofloxacin, sparfloxacin and pefloxacin in both groups. This has been widely reported in most other studies $8,9,12$. Susceptibility to gentamicin (through a cheap drug) might be due to the route of administration which hinder its frequent misuse while the high susceptibility observed in the fluoroquinolones tested may be due to the fact that they are relatively expensive and newer antimicrobial drugs, therefore less available for abuse.

The community-associated $S$. aureus isolates tested exhibited a high level of multi-drug resistance, which calls for great concern. A total of $63 \%$ of the isolates were multiresistant, $89 \%$ were resistant to at least one antibiotic and only $11 \%$ were susceptible to all the antimicrobial drugs. These observations confirm the postulation that healthy members of the community are the highest reservoirs of antimicrobial resistant bacteria ${ }^{19,20}$.

\section{CONCLUSION}

The enormous level of use of antimicrobial drugs indiscriminately or justifiably has great potential for selecting for or enhancing the growth of multi-resistant strains. The results from this study show the need to reassess policies on antimicrobial drugs use within and outside the hospital environment. There is also the need for regular monitoring of the antimicrobial susceptibility status of important pathogens so as to ensure the administration of an effective antibiotic whenever there is need to do so.

\section{REFERENCES}

1. Lowy FD. Staphylococcus aureus Infections. N Engl J Med 1998; 339: 520-532

2. Weems JJ. The many faces of Staphylococcus aureus infection. Postgraduate Medicine (2001); 110 (4): 24-36

3. Archer GL. Staphylococcus aureus: a well-armed pathogen. Clin Infect Dis 1998; 26: $1179-$ 1181

4. Noble WC, Valkenburg HA, Wolters CHL. Carriage of Staphylococcus aureus in random samples of a normal population J Hyg (Lond) 1967; 65: 567-573

5. von Eiff C, Becker K, Machka K, Stammer H, Peters G. Nasal carriage as a source of Staphylococcus aureus bacteremia N. Engl. J. Med. (2001): 344: 11-16.

6. Warner JE, Onderdonk AB. Diversity of toxic shock syndrome toxin 1- positive Staphylococcus aureus isolates. App. Environ. Microbiol. (2004): 70: 6931 - 6935

7. Wenzel RP, Perl TM. The significance of nasal carriage of Staphylococcus aureus and the incidence of postoperative wound infection. $J$ Hospital 1995; 31: 13-24

8. Ehinmidu JO. Antibiotics susceptibility patterns of urine bacterial isolates in Zaria, Nigeria. Trop $J$ Pharm Research 2003; 2: 223-228

9. Onanuga $A$, Oyi AR, Olayinka BO, Onaolapo JA. Prevalence of community-associated multiresistant Staphylococcus aureus among healthy women in Abuja, Nigeria African Journal of Biotechnology (2005); 4(9): 942-945.

10. Cheesbrough $M$. District laboratory practice in tropical countries. Part II; Cambridge University Press. U.K 2002; p.136-142

11. National Committee for Clinical Laboratory Standards: Performance standards for antimicrobial disc susceptibility tests Twelfth informational supplement 2002; M100-S12.

12. Umolu PI, Okoli EN, Izomoh IM. Antibiogram and Betalactamse production of Staphylococcus aureus isolates from different human clinical specimens in Edo state, Nigeria. West Afr med 2002; 21: 124-127

13. Olukoya DK, Asielue JO, Olasupo NA, Ikea JK. Plasmid profile and antibiotic resistance patterns of Staphylococcus aureus isolates from Nigeria. Afr. Med Sci 1995; 24: 135-139

14. Ikeh EL. Methicillin-resistant Staphylococcus aureus (MRSA) at Jos University Teaching Hospital. Afr J Clin Exper Microbiol 2003; 4: 52-62

15. Olayinka BO, Olayinka AT, Onaolapo JA, Olurinola PF. Pattern of resistance to vancomycin and other antimicrobial agents in Staphylococcal isolates in a University teaching hospital. Afr J Clin Exper Microbiol 2005; 6: 46-52

16. Hiramatsu $K$, Hanaki $H$, Ino $T$, Yabuta $K$, Oguri $T$, Tenover FC. Methicillin resistant Staphylococcus aureus clinical strains with reduced vancomycin susceptibility. J Antimicrob. Chemother 1997; 40: 135-136. 


\section{Onanuga \& Onaolapo}

17. Kim MN, Pai CH, Woo JH, Ryu JS, Hiramatsu, K. Vancomycin intermediate Staphylococcus aureus in Korea. J Clin Microbiol 2000; 38: 3879-3881

18. Denis O, Nonhoff C, Byl B, Knoop C, Bobin-Dubreux $S$, Struelens, MJ. Emergence of vancomycinintermediate Staphylococcus aureus in a Belgian hospital: microbiological and clinical features. J Antimicrob Chemother 2002; 50: 383-391
19. Lester SC, Pla MP, Wang F, Schael IP, Jiang $H$, O'Brien TR. The carriage of Escherichia coli resistant to antimicrobial agents by healthy children in Boston, Caracas, Venezuela and Qui Pu, China. N Engl J med 1990; 323: 285289

20. Lamikanra A, Ako-Nai AK, Ogunniyi DA. Transferable antibiotic resistance in Escherichia coli isolated from healthy Nigeria school children. Intern J Antimicrob Agents 1996; 7: 59-64 